\title{
Osteoprotegerin expression and serum values in obese women with type 2 diabetes mellitus
}

\author{
Nearmeen M. Rashad' ${ }^{1} \cdot$ Amal S. El-Shal ${ }^{2,3}$ - Sally M. Shalaby ${ }^{2} \cdot$ Hanim M. Abdel-Nour $^{2} \cdot$ Walaa M. Sarhan $^{2}$
}

Received: 16 June 2021 / Accepted: 31 August 2021 / Published online: 6 September 2021

(c) The Author(s), under exclusive licence to Springer Nature B.V. 2021

\begin{abstract}
Background Obesity and diabetes prevalence are increasing worldwide. We aimed to detect the possible association of osteoprotegerin (OPG) gene expression with visceral adiposity indices and cardiometabolic risk factors among obese women. Methods and results The study enrolled 150 controls and 150 obese cases subdivided into two subgroups non-diabetic $(\mathrm{n}=70)$ and 80 patients with type 2 diabetes mellitus (T2DM). Circulating OPG gene expression levels were figured out by real time PCR (Polymerase Chain Reaction). Serum OPG levels were assessed by Enzyme Linked Immunosorbent Assay. Our results explored that OPG serum levels were lower in the obese women compared to control group $(\mathrm{p}<0.001)$ and obese diabetics had higher serum levels of OPG in comparison to obese non-diabetic patients $(p<0.001)$. Expression levels of OPG were higher in obese women than controls $(\mathrm{p}<0.001)$. Moreover, the blood expression levels of OPG gene were higher in diabetic obese patients than non-diabetics. We found positive correlations between parameters of metabolic syndrome and obesity indices. After adjustment of the traditional risk factors, stepwise linear regression analysis test revealed that OPG expression levels were independently correlated with glycated hemoglobin, high-density lipoprotein-cholesterol, and waist-to-hip ratio.
\end{abstract}

Conclusions OPG mRNA levels were associated with surrogate markers of insulin resistance in Egyptian obese women.

Keywords Type 2 diabetes mellitus · Obesity · Metabolic syndrome · Osteoprotegerin · Real time polymerase chain reaction · Diabetes mellitus

\section{Introduction}

The obesity pandemic is considered a major public health problem, as in this disorder there is increased risk of medical morbidity leading to a significant rise in death rate. Obesity is a common and major risk factor for the metabolic syndrome (MetS) [1]. Obesity and Insulin resistance (IR) are key phenotype contributing to atherogenic and diabetogenic profiles [2].

Amal S. El-Shal

amalelshal@gmail.com; amalelshal@yahoo.com;

amalelshal@zu.edu.eg; ASAbdelazim@medicine.zu.edu.eg

1 Internal Medicine Department, Faculty of Medicine, Zagazig University, Zagazig, Egypt

2 Medical Biochemistry Department, Faculty of Human Medicine, Zagazig University, Zagazig, Egypt

3 Medical Biochemistry Department and Molecular Biology, Military Armed Forces College of Medicine (AFCM), Cairo, Egypt
The prevalence is escalating significantly in many nations worldwide. In Egypt, there is a remarkable increase in obesity with more than one third of the entire population being obese. A particular issue in Egypt is that prevalence of obesity is more than double among females $(46 \%)$ as compared to males (22\%) [3]. This is a growing concern as obese subjects are at increased risk of developing diabetes, high blood pressure, dyslipidemia, in addition to coronary heart disease, stroke and cancers [4].

A common argument against body mass index (BMI) as an anthropometric measurement of obesity is that BMI is not discriminating between the lean and fat body mass. The recent obesity index: body adiposity index (BAI) is based on both hip circumference and height. Thus, BAI overcomes the limitation of BMI [5]. The visceral adiposity index (VAI) is based on both anthropometric; BMI and waist circumference (WC) in combination with triacylglycerol levels (TAG) and high-density lipoprotein—cholesterol (HDL-c) [6].

It is an important clinical consideration that obesity is a condition of low-grade inflammation [7]. Noteworthy, 
increasing clues showed that low-grade inflammation associated with obesity lead to the continuous activation of the immune system [7].

Osteoprotegerin (OPG) is a glycoprotein cytokine, which acts in cooperation with the receptor activator of receptor activator of nuclear factor $\kappa \mathrm{B}$ ligand (RANKL), and tumor necrosis factor (TNF) -related apoptosis-inducing ligand. The OPG gene is approximately $29 \mathrm{kB}$ of the genome on chromosome 8 and constitutes 5 exons [8]. Mounting evidence explored that OPG is expressed in vascular smooth muscle cells (VSMCs), osteoblasts and endothelial cells (ECs) [8].

Studies suggested that circulating OPG derived from ECs was associated with active atherosclerosis [9]. Moreover, strong associations between OPG levels and ischemic heart disease, insulin resistance (IR), obesity, stroke as well as decompensated heart failure have been showed [10-12]. Recent studies showed that RANK/RANKL/OPG pathway is an important for the regulation of obesity [13, 14]. Yet, the pathological connection between obesity, metabolic syndrome and this pathway is not clear till now. So, further studies are needed for better clarification of the bounds of this association.

According to our knowledge, it is the first study explored the association between OPG gene expression and obesity as well as cardio metabolic risk factors. To address this need, the objective of the present work was to investigate the expression and serum levels of OPG in relation to new obesity indices (BAI and VAI) as well as cardio-metabolic risk factors among Egyptian obese women.

\section{Subjects and methods}

\section{Subjects}

This study included 300 nonrelative subjects. One hundred fifty obese females (BMI > 30) enlisted from Diabetes and Endocrinology outpatient clinic of Internal Medicine Department of Zagazig University Hospitals and 150 healthy lean controls that were matched to cases by age and gender.

Obese women were categorized into two subgroups according to their fasting blood glucose (FBG) based criteria reported by the American Diabetes Association [ADA] in 2015 into: non-diabetic patients (FBG $<126 \mathrm{mg}$ / dl) $(n=70)$ and 80 cases with T2DM (FBG $\geq 126 \mathrm{mg} / \mathrm{dl})$. All individuals were submitted to careful history taking and complete clinical assessment including blood pressure, waist circumference (WC) and hip circumference (HC). Anthropometric measures, including BMI $(\mathrm{kg} /$ meters ${ }^{2}$ ), waist-to-hip ratio $($ WHR $)=$ waist circumference $(\mathrm{cm}) /$ hip circumference $(\mathrm{cm})$, and WHtR was calculated as the waist $(\mathrm{cm}) /$ height $(\mathrm{cm})$. Moreover, VAI in women was calculated as follows: $(\mathrm{WC}(\mathrm{cm}) /(36.58+(\mathrm{BMI} \times$ $1.89) \times(\mathrm{TG} / 0.81) \times(1.52 / \mathrm{HDL}-\mathrm{c})[12]$. Finally, BAI is approximately equal to the percentage of body fat. It is calculated as [5].

The metabolic syndrome (MetS) was diagnosed depending on International Diabetes Federation criteria. Patients diagnosed with the MetS if she has a WC $(\geq 80 \mathrm{~cm})$ with any two of the following risk factors: (a) FBG $\geq 100 \mathrm{mg} / \mathrm{dl}$ or previously diagnosed impaired fasting glucose (b) blood pressure $[\mathrm{BP}] \geq 130 / 85 \mathrm{mmHg}$ or taking medical treatment for hypertension (c) TAG $\geq 150 \mathrm{mg} / \mathrm{dl}$ (d) HDL-c $<50 \mathrm{mg} /$ dl.

Patients with cancer, stroke, or liver, kidney, thyroid, parathyroid, and cardiovascular or any active inflammatory diseases have been excluded from this study. None of the participants had a history of bariatric or liposuction surgery, as well as receiving medications for weight reduction and osteoporosis, for example strontium ranelate, which may affect OPG, levels. No concurrent minor infection was detected during the study or in the month preceding the study. Ethical committee, Faculty of Human Medicine; Zagazig University approved this research protocol, and enrolled participants assigned informed written consent.

\section{Biochemical analysis}

A trained nurse collected the blood samples after a $10-12 \mathrm{~h}$ fasting period for measurement of serum TC, HDL-c and TAG. The low-density lipoprotein (LDL-c) level was determined using the Friedewald formula [15]. Glucose concentrations were estimated using the glucose oxidase method (Spinreact, Spain). Fasting serum insulin concentration was determined by human insulin ELISA kit (Biosource, Belgium). Homeostasis models were calculated Homeostasis model insulin resistance assessment (HOMA-IR) and ®-cell function (HOMA- $($ ) were calculated.

\section{Measurement of serum osteoprotegerin concentration}

Serum OPG concentration was quantified using the enzymelinked immunosorbent assays (ELISA) (RayBiotech, USA).

\section{RNA extraction and complementary DNA (cDNA)}

Total RNA was extracted from the whole blood using QIAamp RNA [Qiagen; USA] according to the manufacturer's protocol. The extracted RNA had been reversely transcribed using QuantiTect [Qiagen; USA] according to the manufacturer's guides. 


\section{Analysis of OPG expression in blood by real time polymerase chain reaction (RT-PCR)}

The OPG mRNA gene expression in blood was done by RTPCR using StepOne ${ }^{\mathrm{TM}}$ system (Applied Biosystems). Primers of OPG were as follows: forward primer: 5'-TGCTGT TCCTACAAAGTTTACG-3'; reverse primer: 5'-CTTTGA GTGCTTTAGTGCGTG-3'; $\beta$-Actin forward primer: 5'-CGT GACATTAAGGAGAAGCTGTGC-3' and reverse primer: 5'-CTCAGGAGGAGCAATGATCTTGAT-3', as a housekeeping gene [16]. The PCR was done in a final volume (25 $\mu$ l) holding $12.5 \mu \mathrm{l} 2 \times$ QuantiFast SYBR Green PCR Master Mix, $1 \mu \mathrm{M}$ of each primer and $7.5 \mu \mathrm{cDNA}$ with this protocol: $95^{\circ} \mathrm{C}$ for $5 \mathrm{~min}, 40$ cycles of denaturation at $95^{\circ} \mathrm{C}$ for $10 \mathrm{~s}$, annealing and extension at $56^{\circ} \mathrm{C}$ for $30 \mathrm{~s}$. OPG The expression was reported as the Delta cycle threshold $(\Delta$ $\mathrm{Ct}$ ) value. The relative expression of mRNA was calculated utilizing the comparative CT method and OPG expression levels were normalized to $\beta$-actin mRNA using the $\Delta \mathrm{CT}$ method. All kits were purchased from QIAGEN (Valencia, USA).

\section{Statistical analysis}

Descriptive statistics included means and SDs for continuous variables, and numbers and percentages for categorical variables. Group comparisons were performed by a $\chi^{2}$ test or analysis of variance as proper. Pearson correlation coefficient was used to assess the association between obesity indices and other studied metabolic parameters in obese women. Receiver operating characteristic (ROC) analysis was performed to assess the potential accuracy of OPG; the area under the curve (AUC), and the cutoff values for diagnosis of T2DM among obese patients. Stepwise multiple linear regression analyses were used to detect the main predictors of OPG mRNA and serum values in the obese group. Logistic regression analysis was performed to assess the predictor's powers of expression as well as serum levels of OPG in the prediction of T2DM among obese patients. SPSS V.21.0 (SPSS, USA) was applied for all analyses. P Value $<0.05$ was considered statistically significant.

\section{Results}

\section{Anthropometric and biochemical data of study groups}

They were shown in Table 1 . As expected, obese patients had significantly higher values of systolic blood pressure (SBP), diastolic blood pressure (DBP), fasting blood glucose (FBG), HbA1c, fasting serum insulin, HOMA-IR, TC, LDLc, and TAG levels compared to lean controls. Moreover, all obesity indices and parameters (WC, BMI, WHR, WHtR, BAI and VAI) were significantly higher in obese women compared to leans. On the contrary, obese patients had significant lower levels of HOMA- ${ }^{\circledR}$ than in healthy lean individuals $(\mathrm{p}<0.001)$.

\section{Circulating OPG levels (pmol/L) and relative OPG expression levels in study groups}

In the present study obese women had lower OPG serum levels than the controls $(5.06 \pm 0.87$ vs $6.56 \pm 0.82, \mathrm{p}<0.001)$. However, obese diabetics had higher serum OPG values when compared to obese non-diabetic patients $(5.6 \pm 0.51$ vs. $4.4 \pm 0.73, \mathrm{p}<0.001$ ) (Fig. 1A). In obese group, the blood expression levels of OPG were significantly higher than control group $(2.3 \pm 0.73$ vs. $1.53 \pm 0.32, \mathrm{p}<0.001)$. Additionally, in diabetic obese patients, the blood expression levels of OPG were significantly higher than non-diabetics patients $(2.83 \pm 0.61$ vs. $1.53 \pm 0.32)(\mathrm{p}<0.001)($ Fig. $1 B)$.

\section{General characteristics of obese patients stratified by diabetic and non-diabetic obese patients}

We found statistically significant higher values of $\mathrm{FBG}$, serum insulin, HbA1c, HOMA-IR, SBP, DBP, LDL-c, TC levels, OPG expression levels, serum OPG level as well as VAI, BMI, WHtR and BAI in obese T2DM patients than in non-diabetic obese $(\mathrm{p}<0.001)$. In contrast, obese diabetic patients had significantly lower levels of HOMA-B than in obese non-diabetics, $(\mathrm{p}<0.001)$. However, there were no statistically significant differences between obese nondiabetic and T2DM patients as respect to other parameters $(\mathrm{p}>0.05)$ (Table 2).

\section{Correlations between anthropometric measures with parameters of MetS in obese patients}

Our results showed significant positive correlations between parameters of MetS including WC, SVP, low HDL (High Density Lipoprotein) as well as TAG with all anthropometric measures in obese cases (BMI, WHR, WHtR, BAI and VAI). Interestingly, among obesity indices, the highest positive correlation found between VAI and parameters of MetS $(\mathrm{p}<0.001)($ Table 3$)$.

\section{Multiple stepwise linear regression analyses in obese patients to assess the main independent parameters associated with OPG expression levels}

Stepwise linear regression analysis test revealed that OPG expression levels were independently correlated with HbA1c, HDL-c, and WHR ( $<0.001)$ (Table 4). 
Table 1 Anthropometric and biochemical characteristics of the studied groups

\begin{tabular}{lllc}
\hline & $\begin{array}{l}\text { Lean healthy control } \\
(n=150)\end{array}$ & $\begin{array}{l}\text { Obese patients } \\
(n=150)\end{array}$ & p value \\
\hline Age (years) & $44.58 \pm 11.4$ & $43.64 \pm 8.2$ & 0.15 \\
Sex (male/female) & $15 / 35$ & $42 / 108$ & 0.93 \\
Body mass index $\left(\mathrm{kg} / \mathrm{m}^{2}\right)$ & $21.4 \pm 1.15$ & $32.8 \pm 13.95$ & $<0.001^{*}$ \\
Waist circumference $(\mathrm{cm})$ & $91.4 \pm 14.71$ & $108.01 \pm 13.8$ & $<0.001^{*}$ \\
Waist/hip ratio & $0.94 \pm 0.013$ & $1.05 \pm 0.176$ & $<0.001^{*}$ \\
Waist/height ratio & $0.54 \pm 0.09$ & $0.64 \pm 0.089$ & $<0.001^{*}$ \\
Body adiposity index (BAI) & $22.97 \pm 8.7$ & $35.86 \pm 15.4$ & $<0.001^{*}$ \\
Visceral adiposity index (VAI) & $0.89 \pm 0.14$ & $5.92 . \pm 1.34$ & $<0.001^{*}$ \\
Systolic blood pressure (mmHg) & $116.2 \pm 4.79$ & $134.5 \pm 16.2$ & $<0.001^{*}$ \\
Diastolic blood pressure (mmHg) & $75.3 \pm 4.21$ & $84.03 \pm 9.13$ & $<0.001^{*}$ \\
Total cholesterol (mg/dl) & $166.1 \pm 7.85$ & $221.2 \pm 75.2$ & $<0.001^{*}$ \\
Triacylglycerol (mg/dl) & $129.5 \pm 12.3$ & $189.9 \pm 34.6$ & $<0.001^{*}$ \\
LDL cholesterol (mg/dl) & $91.8 \pm 0.98$ & $135.3 \pm 73.9$ & $<0.001^{*}$ \\
HDL cholesterol (mg/dl) & $48.4 \pm 4.41$ & $46.6 \pm 8.95$ & 0.178 \\
Fasting blood glucose (mg/dl) & $86.8 \pm 5.08$ & $147.9 \pm 55.9$ & $<0.001^{*}$ \\
Fasting serum insulin $(\mu \mathrm{U} / \mathrm{ml})$ & $7.4 \pm 1.82$ & $13.18 \pm 6.37$ & $<0.001^{*}$ \\
HbA1c (\%) & $5.36 \pm 0.41$ & $7.56 \pm 1.76$ & $<0.001^{*}$ \\
HOMA-IR & $1.57 \pm 0.40$ & $5.7 \pm 4.14$ & $<0.001^{*}$ \\
HOMA-B & $118.6 \pm 37.1$ & $85.8 \pm 27.9$ & $<0.001^{*}$ \\
Serum OPG (pmol/L) & $6.56 \pm 0.82$ & $5.06 \pm 0.87$ & $<0.001^{*}$ \\
OPG mRNA expression & $1.53 \pm 0.32$ & $2.3 \pm 0.73$ & $<0.001^{*}$ \\
\hline
\end{tabular}

HOMA-IR homeostasis model assessments of Insulin resistance, HOMA- $\beta$ an index of $\beta$-cell function, $O P G$ osteoprotegerin

$* \mathrm{p}<0.05$ when compared with control group
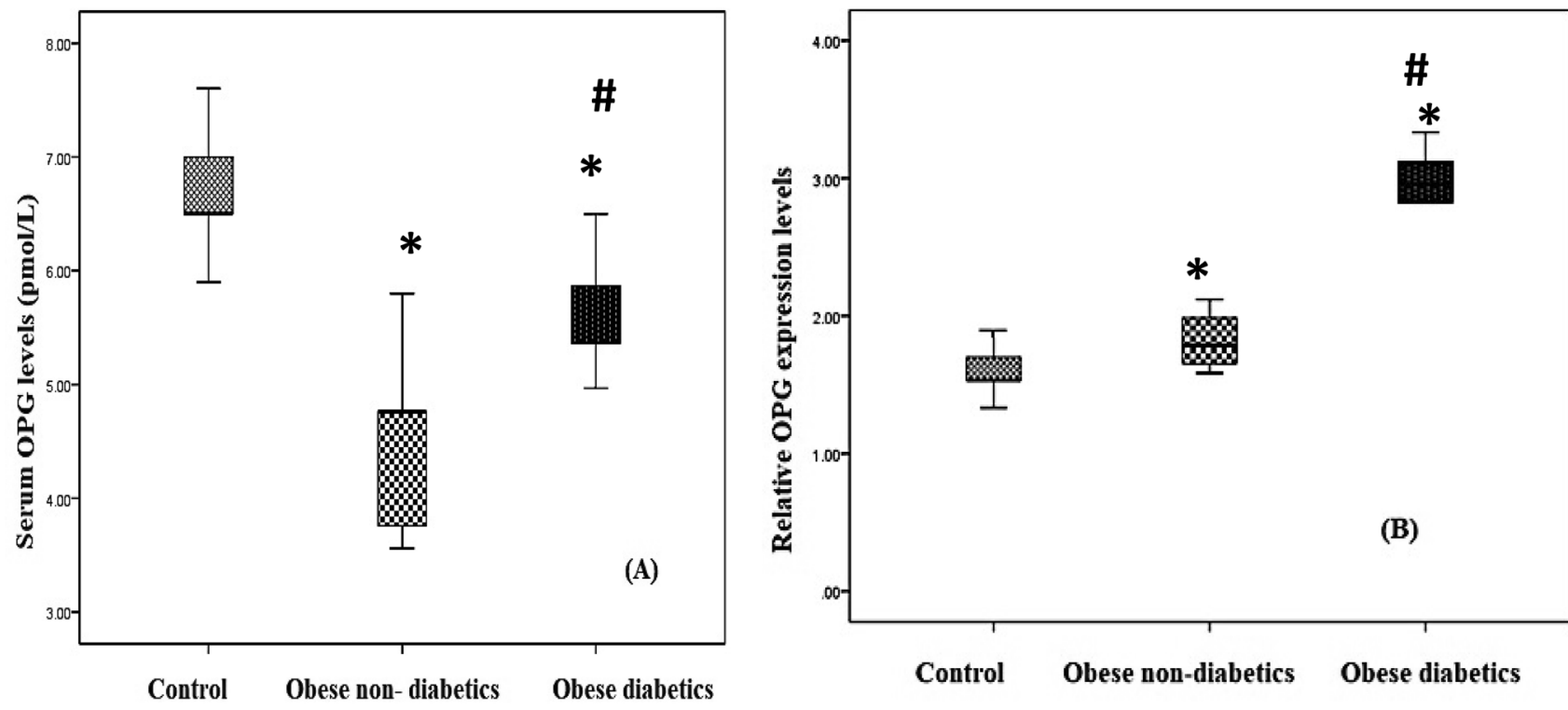

Fig. 1 A Serum OPG levels (pmol/L) in studied groups; B relative OPG expression levels in studied groups. * ${ }^{*}<0.001$ when compared to control, ${ }^{\#} \mathrm{p}<0.001$ when compared to obese non-diabetics 
Table 2 Laboratory and anthropometric parameters in non-diabetic obese and T2DM obese groups

\begin{tabular}{lllc}
\hline & $\begin{array}{l}\text { Obese non-diabetic } \\
\text { patients }(\mathrm{n}=70)\end{array}$ & $\begin{array}{l}\text { Obese diabetic patients } \\
(n=80)\end{array}$ & p value \\
\hline Age (years) & $42.3 \pm 5.8$ & $41.5 \pm 8.02$ & 0.49 \\
Sex (male/female) & $22 / 48$ & $20 / 60$ & 0.49 \\
Body mass index $\left(\mathrm{kg} / \mathrm{m}^{2}\right)$ & $33.30 \pm 4.29$ & $32.38 \pm 3.6$ & 0.103 \\
Waist circumference $(\mathrm{cm})$ & $113.2 \pm 15.35$ & $103.8 \pm 10.22$ & $<0.001^{*}$ \\
Waist/hip ratio & $1.02 \pm 0.15$ & $1.079 \pm 0.19$ & 0.050 \\
Waist/height ratio & $0.67 \pm 0.09$ & $0.6 \pm 0.065$ & $<0.001^{*}$ \\
Body adiposity index (BAI) & $26.6 \pm 4.4$ & $43.9 \pm 11.4$ & $<0.001^{*}$ \\
Visceral adiposity index $(\mathrm{VAI})$ & $6.98 \pm 1.28$ & $8.74 \pm 0.96$ & $<0.001^{*}$ \\
Systolic blood pressure $(\mathrm{mmHg})$ & $119.1 \pm 4.77$ & $148.12 \pm 8.39$ & $<0.001^{*}$ \\
Diastolic blood pressure $(\mathrm{mmHg})$ & $77.2 \pm 5.32$ & $90 \pm 7.46$ & $<0.001^{*}$ \\
Total cholesterol (mg/dl) & $245.9 \pm 95.96$ & $200.7 \pm 41.55$ & $<0.001^{*}$ \\
Triacylglycerol $(\mathrm{mg} / \mathrm{dl})$ & $193.12 \pm 46.7$ & $187.9 \pm 17.4$ & 0.359 \\
LDL cholesterol $(\mathrm{mg} / \mathrm{dl})$ & $159.9 \pm 93.7$ & $114.6 \pm 42.11$ & $<0.001^{*}$ \\
HDL cholesterol $(\mathrm{mg} / \mathrm{dl})$ & $47.4 \pm 8.94$ & $45.9 \pm 9.02$ & 0.324 \\
Fasting blood glucose $(\mathrm{mg} / \mathrm{dl})$ & $89.3 \pm 12.37$ & $199.1 \pm 9.24$ & $<0.001^{*}$ \\
Fasting serum insulin $(\mu \mathrm{IU} / \mathrm{ml})$ & $7.78 \pm 2.98$ & $17.9 \pm 4.46$ & $<0.001^{*}$ \\
HbA1c $(\%)$ & $5.77 \pm 0.67$ & $9.13 \pm 0.3$ & $<0.001^{*}$ \\
HOMA-IR & $2.9 \pm 0.45$ & $5.9 \pm 0.67$ & $<0.001^{*}$ \\
HOMA-B & $96.5 \pm 10.03$ & $60.4 \pm 12.07$ & $<0.001^{*}$ \\
Serum OPG (pmol/L) & $4.4 \pm 0.73$ & $5.6 \pm 0.51$ & $<0.001^{*}$ \\
OPG mRNA expression & $1.53 \pm 0.32$ & $2.83 \pm 0.61$ & $<0.001^{*}$ \\
\hline
\end{tabular}

HOMA-IR homeostasis model assessments of Insulin resistance, HOMA- $\beta$ an index of $\beta$-cell functions, $O P G$ osteoprotegerin

$* \mathrm{p}<0.05$ when compared with obese non-diabetic patient's group

Table 3 Pearson correlation coefficient between anthropometric indices and parameters of metabolic syndrome among obese patients

\begin{tabular}{|c|c|c|c|c|c|c|}
\hline & & $\begin{array}{l}\text { Body mass index } \\
\left(\mathrm{kg} / \mathrm{m}^{2}\right)\end{array}$ & Waist/hip ratio & Waist/height ratio & BAI & VAI \\
\hline \multirow[t]{2}{*}{ Waist circumference $(\mathrm{cm})$} & $r$ & 0.747 & 0.121 & 0.983 & 0.125 & 0.228 \\
\hline & $P$ & $<0.001 *$ & 0.139 & $<0.001 *$ & 0.128 & $<0.001 *$ \\
\hline \multirow[t]{2}{*}{ Systolic blood pressure (mmHg) } & $r$ & 0.255 & 0.125 & 0.235 & 0.527 & 0.326 \\
\hline & $P$ & $<0.01 *$ & 0.062 & 0.004 & $<0.001 *$ & 0.062 \\
\hline \multirow[t]{2}{*}{ Diastolic blood pressure $(\mathrm{mmHg})$} & $r$ & 0.140 & 0.122 & 0.103 & 0.139 & 0.471 \\
\hline & $P$ & 0.089 & 0.138 & 0.212 & 0.091 & $<0.001^{*}$ \\
\hline \multirow[t]{2}{*}{ Triacylglycerol (mg/dl) } & $r$ & 0.833 & 0.389 & 0.425 & 0.230 & 0.804 \\
\hline & $P$ & $<0.001 *$ & $<0.001 *$ & $<0.001 *$ & $0.01 *$ & $<0.001^{*}$ \\
\hline \multirow[t]{2}{*}{ HDL cholesterol (mg/dl) } & $r$ & -0.383 & -0.356 & -0.020 & -0.383 & -0.592 \\
\hline & $P$ & $<0.001^{*}$ & $<0.001 *$ & 0.811 & $<0.001^{*}$ & $<0.001^{*}$ \\
\hline \multirow[t]{2}{*}{ Fasting blood glucose (mg/dl) } & $r$ & 0.355 & 0.362 & 0.144 & 0.539 & 0.243 \\
\hline & $P$ & $<0.001 *$ & $<0.001^{*}$ & 0.080 & $<0.001 *$ & $0.01 *$ \\
\hline
\end{tabular}

$B A I$ body adiposity index, $V A I$ visceral adiposity index

\section{Logistic regression analysis evaluating the association of OPG expression and serum values with T2DM among obese patients}

After adjusting for the traditional risk factors, the logistic regression analysis test was done to evaluate the predictors of obesity among studies subjects. Serum OPG levels were statistically significant predictor of obesity $(\mathrm{p}<0.001)$ with odds ratio was $10.668,95 \% \mathrm{CI}=3.349-33.985$. Regarding OPG expression, the odds ratio was 7.57, 95\% $\mathrm{CI}=2.894-19.081$ (Table 5). Among anthropometric 
Table 4 Multiple stepwise linear regression analysis to test the influence of the main independent variables on OPG expression levels (dependent variable) among obese patients
Table 5 Logistic regression analyses of OPG expression and serum OPG levels as well as anthropometric measures in obese versus lean subjects

\begin{tabular}{|c|c|c|c|c|c|c|c|}
\hline \multirow[t]{2}{*}{ Model } & \multicolumn{2}{|c|}{$\begin{array}{l}\text { Unstandardized } \\
\text { Coefficients }\end{array}$} & \multirow{2}{*}{$\begin{array}{l}\text { Standardized } \\
\text { Coefficients } \\
\text { Beta }\end{array}$} & \multirow{2}{*}{$\mathrm{t}$} & \multirow[t]{2}{*}{$\mathrm{p}$ value } & \multicolumn{2}{|c|}{$\begin{array}{l}95.0 \% \text { Confidence interval } \\
\text { for B }\end{array}$} \\
\hline & $\beta$ & Std. error & & & & Lower bound & Upper bound \\
\hline \multicolumn{8}{|l|}{ Model 1} \\
\hline Constant & 0.304 & 0.194 & - & 1.567 & 0.119 & -0.079 & 0.688 \\
\hline HbA1c (\%) & 0.277 & 0.025 & 0.672 & 11.031 & $<0.001^{*}$ & 0.227 & 0.326 \\
\hline \multicolumn{8}{|l|}{ Model 2} \\
\hline Constant & 1.156 & 0.293 & - & 3.943 & $<0.001 *$ & 0.577 & 1.735 \\
\hline HbA1c (\%) & 0.290 & 0.024 & 0.705 & 11.941 & $<0.001 *$ & 0.242 & 0.338 \\
\hline Waist/hip ratio & 0.905 & 0.241 & 0.222 & 3.759 & $<0.001^{*}$ & -1.381 & -0.429 \\
\hline \multicolumn{8}{|l|}{ Model 3} \\
\hline Constant & 1.536 & 0.330 & - & 4.658 & $<0.001^{*}$ & 0.884 & 2.188 \\
\hline HbAlc (\%) & 0.291 & 0.024 & 0.706 & 12.156 & $<0.001 *$ & 0.244 & 0.338 \\
\hline Waist/hip ratio & 0.651 & 0.260 & 0.160 & 2.506 & $0.03 *$ & 1.165 & 0.138 \\
\hline HDL cholesterol & -0.014 & 0.006 & -0.150 & -2.382 & $0.02 *$ & -0.025 & -0.002 \\
\hline
\end{tabular}

\begin{tabular}{lrrrrrrr}
\hline & \multicolumn{1}{l}{$\beta$} & S.E & \multicolumn{1}{l}{$\mathrm{t}$} & $\mathrm{p}$ value & Odds ratio & \multicolumn{2}{l}{ 95\% CI } \\
\cline { 6 - 8 } & & & & & & & \multicolumn{2}{c}{ Lower } & Upper \\
\hline OPG (pmol/L) & 2.367 & 0.591 & 16.036 & $<0.001$ & 10.668 & 3.349 & 33.985 \\
OPG expression & 2.024 & 0.491 & 17.020 & $<0.001$ & 7.570 & 2.894 & 19.803 \\
Waist/height ratio & -8.668 & 3.191 & 7.379 & 0.007 & 0.003 & 0.007 & 0.089 \\
Waist/hip ratio & 2.442 & 1.888 & 1.672 & 0.196 & 11.495 & 0.284 & 465.360 \\
\hline
\end{tabular}
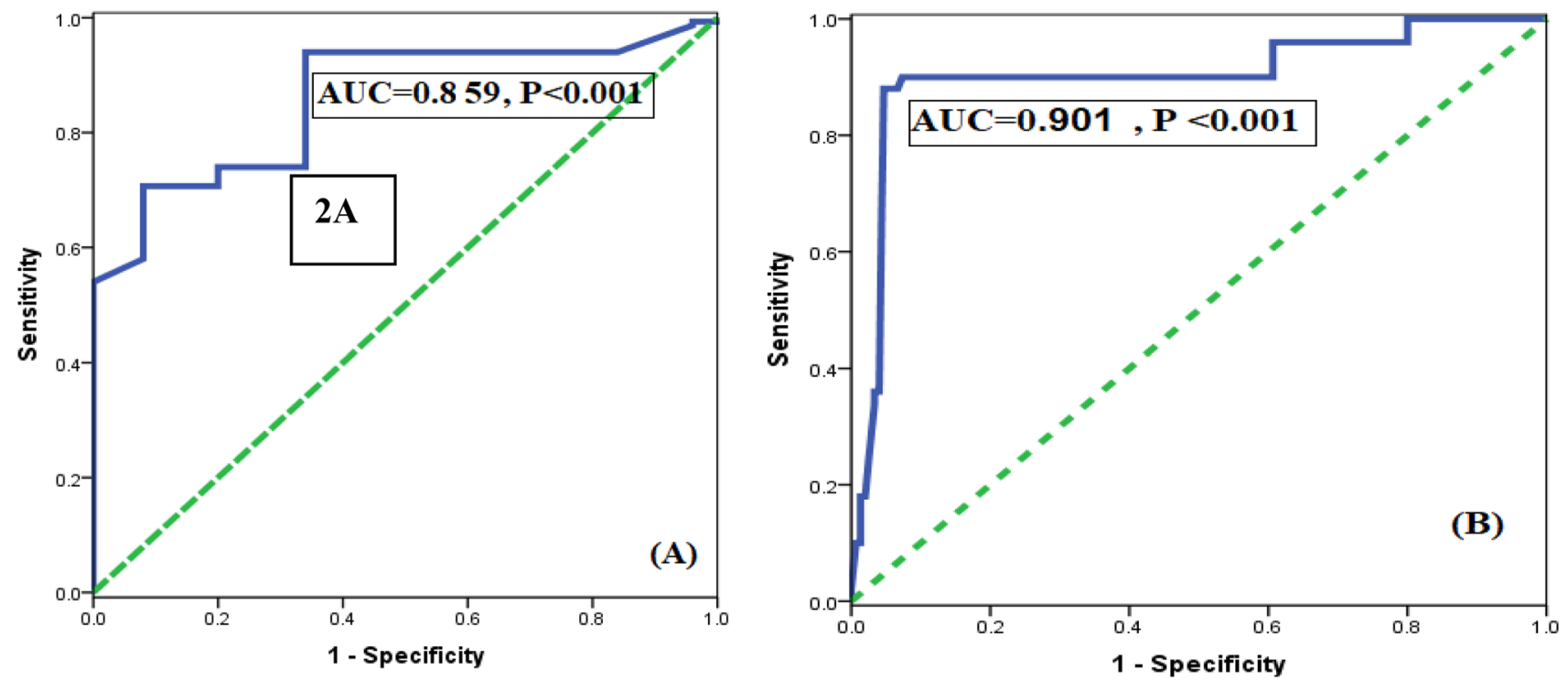

Fig. 2 A ROC curve for utility of for OPG expression levels in discriminating lean control from obese patients; B ROC curve for utility of for serum OPG levels in discriminating lean control from obese women 
measurements the only tested measures were WHR ratio with odds ratio was $00.003,95 \% \mathrm{CI}=0.007-0.089$.

\section{Accuracy of OPG expression and serum levels for discriminating obese from lean control by ROC analyses}

We further investigated the possible diagnostic value of OPG expression and OPG serum levels by ROC curves (Fig. 2A, $\mathrm{B}$, respectively). For discrimination of obese among from lean subjects, the cutoff values of OPG expression levels and serum levels were 1.943 and 5.883 and the AUC were [0.859 (95\% CI $=0.806-0.911)$ and $0.901(95 \% \mathrm{CI}=0$ 0.841-0.962), respectively, $\mathrm{P}<0.001]$. Additionally, the sensitivities and the specificities of OPG expression levels were (92 and 70.7\%), and OPG serum level (90 and 99.7\%), respectively. Thus, OPG expression and serum OPG levels could be useful diagnostic biomarkers discriminating obese from lean subjects.

\section{Accuracy of OPG expression and serum levels for discriminating type 2 diabetes mellitus among obese by ROC analysis}

We further looked into the possible diagnostic value of OPG expression (A) and OPG serum levels (B) by ROC curves were presented in (Fig. 3). In obese patients, when we discriminate T2DM among non- diabetic patients, the cutoff values of OPG mRNA levels and serum levels were 2.2267 and 5.263 and the AUC were $[0.833(95 \% \mathrm{CI}=0.821-0.946)$ and 0.950 (95\% CI $=0.908-0.991)$, respectively, $\mathrm{p}<0.001$ for each]. To boot, the sensitivities and the specificities of OPG expression were (90 and 86.2\%), and OPG serum levels (95.7 and $96.4 \%$ respectively).

\section{Discussion}

Obesity is an established risk factor for T2DM and a vital component of MetS. Not surprisingly, therefore, the increasing prevalence of obesity is being paralleled to similar increases in the number of persons with T2DM or MetS [4]. Considerable evidence implicates inflammation as a crucial component in the pathophysiology of obesity and diabetes.

Osteoprotegerin is a member of the TNF receptor superfamily. It is a receptor of TNF-related apoptosis-inducing ligand (TRAIL) playing a role in immune regulation and cell survival [17]. TNF- $\alpha$, interleukin-1 (IL-1), IL-18 and transforming growth factor- $\beta$ (TGF- $\beta$ ) were known to upregulate OPG mRNA levels [18-20]. On the other hand, glucocorticoids, parathormone hormone (PTH) and prostaglandin E2 $\left(\mathrm{PGE}_{2}\right)$ can inhibit the expression of $\mathrm{OPG}$ [21-23]. Emerging evidence showed that estrogens stimulate OPG expression [24]. Based on these findings, in the present study we include women only and excluded any patients

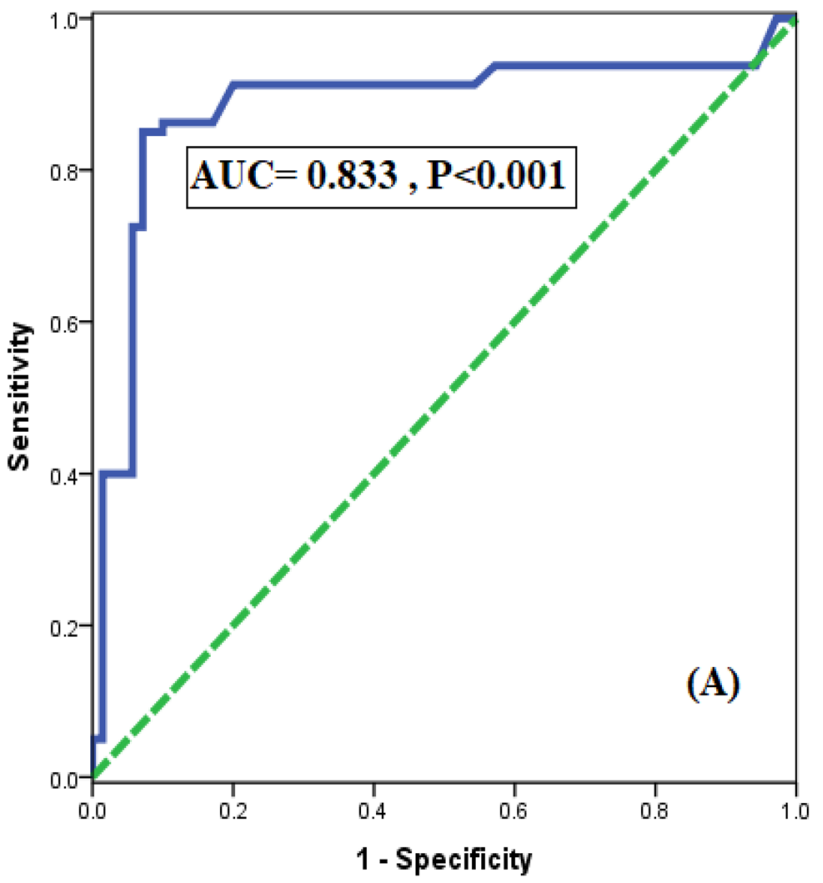

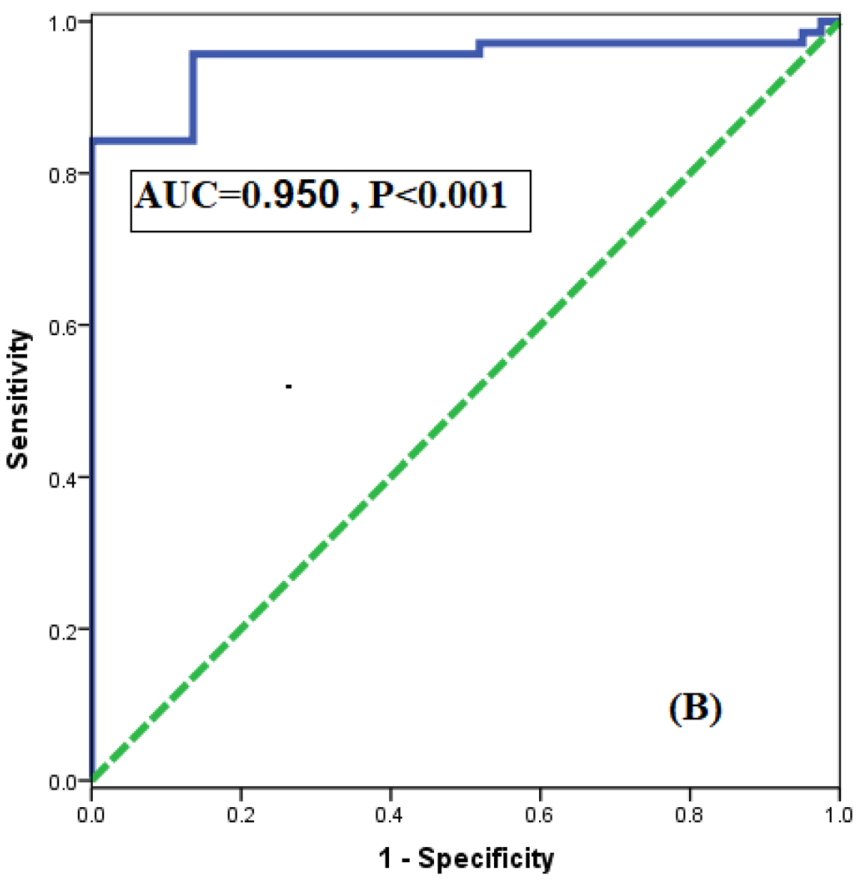

Fig. 3 A ROC curve for utility of OPG expression in discriminating obese women with T2DM from those without diabetes; B ROC curve for utility of serum OPG levels in discriminating obese patients with T2DM from those without diabetes 
with parathyroid disorders or receive medication affect OPG mRNA or serum levels.

Our results explored that obese woman had significantly lower values of serum OPG levels compared to lean controls. The present study is consistent with others as they found the serum OPG concentration has significantly lower levels in obese patients in relation to lean controls [25-27]. Holecki et al. explained that the production and levels of OPG was correlated to parathormone hormone among patients with morbid obesity [25]. Zaky et al. [28] reported lower level of OPG in obese adult premenopausal females in comparison to lean age matched females. They attributed that to it may be related to lower activity of bone metabolism in obese women and less compensating production of OPG [28]. Stanik et al. found a negative relationship between OPG and BMI $(r=-0.098, \mathrm{p}<0.001)$ in a sample of 1325 children and adolescents [29]. Recently, Nesaee et al. [12] found the mean osteoprotegerin level was significantly lower in the obese children than in the non-obese one. In the contrary to our study, Ayina et al. found that OPG had higher levels in obese than in normal subjects [30]. Other results that compared obese and normal body weight individuals in terms of circulating OPG level reported no differences between them [31]. Kotanidou et al. showed OPG levels did not differ significantly between obese subjects and controls in the total sample $(\mathrm{p}=0.133)$. However, in the adolescent's subgroup, serum OPG levels were significantly increased in obesity $(\mathrm{p}=0.019)$. After stratifying participants according to their IR status, only subjects with both obesity and IR exhibited increased OPG levels compared to controls $(\mathrm{p}<0.001)$. They explained that as obesity per se is not the potent factor for the increase of OPG levels; indeed, IR going with obesity seems to exert a fundamental role in OPG upregulation [32]. The discrepancy of results regarding OPG levels in obesity may partly arise from the difference in the patient population among these studies.

We analyzed for the first time OPG gene expression in obese and lean people. We found an up regulation of OPG expression in the obese women when compared to lean subjects. These results confirmed by Toffoli et al. who found OPG mRNA levels were significantly increased in aorta and hearts of diabetic mice as compared to control group [33]. Moreover, Chang et al. showed that OPG expression was increased in hyperglycemic rat aortic VSMCs, while RANKL expression was decreased [34]. In the present study, there is controversy between the expression and serum levels of OPG as it was upregulated in the obese when compared to leans while the serum levels were lower in obese than lean women. It was suggested that first, there are many complicated and varied post-transcriptional mechanisms involved in turning mRNA into protein that are not yet sufficiently well-defined to be able to compute protein concentrations from mRNA; second, proteins may differ in their in vivo half-lives [35].

The present study showed that obese diabetics had higher serum levels of OPG and upregulation of OPG gene expression compared to obese non-diabetic patients. Many studies found significant increase of serum OPG in T2DM and T1DM compared to normal controls [36-38]. In line with our results, an Egyptian study conducted by Ahmed et al. found that the serum OPG had significantly higher levels in diabetic patients than in the healthy group and more in diabetic patients with MetS than in those without MetS [39]. Alharbi et al. found that serum OPG level was significantly elevated in obese with insulin resistance patients compared to control subjects [40]. Others cannot find any statistical difference of OPG among subjects with or without MetS [41].

Interestingly, we found that $\mathrm{HbA} 1 \mathrm{c}$ and $\mathrm{HDL}-\mathrm{c}$ are the main predictors of OPG gene expression among obese subjects. In accordance with our findings, Toffoli et al. showed that both dyslipidemia and T2DM can affect OPG expression levels in the cardiovascular system and these changes could contribute to atherosclerosis [33]. Gümüş et al. found that OPG levels were higher in patients with poor glycemic control and that they may be indicators of disease severity [42]. On the contrary, Sassi et al. did not find any significant increase in OPG regardless to glycemic control [43].

To illuminate the relationship between anthropometric measures with the parameters of MetS, we found significant positive correlations between parameters of MetS including WC, SBP and DBP, low HDL-c as well as TAG with all anthropometric measures in obese cases (BMI, WHR, whiter, BAI and VAI). Interestingly, among obesity indices, the highest positive correlation was found between VAI and parameters of MetS in this study and in previous researches $[44,45]$.

In conformity with our finding, Amato et al. among an age-stratified a Caucasian Sicilian population, cutoff points of VAI were proved to be strongly related to MetS, they explained that VAI stands for physical (BMI and WC) and metabolic parameters (TAG and HDL-c), may, indirectly show other non-classical risk factors, i.e., cytokines and plasma-free fatty acids [6].

In the current study, we detected significant positive correlation between BAI and all parameters of MetS except WC and DBP among obese cases. Like our results, Bergman et al. reported that BAI is a useful parameter to evaluate adiposity in Caucasian population. Furthermore, they reasoned that it is more practical as well as less demanding than other complex mechanical strategies [5].

Interestingly, the present work is the initiative to concentrate on an OPG expression level in obesity and its correlations with obesity indices; BAI, VAI as well as parameters of MetS. The main finding of the present work is the 
independent correlation between OPG expression level and anthropometric measures as well as parameters of MetS. These results matched with those conducted by GannageYared et al. [31] and Kotanidou et al. [32], they found a positive correlation between OPG and HOMA-IR. There are noteworthy useful impacts of OPG on vascular tissues as it is associated with endothelial dysfunction and IR. These effects were backed up previously by other studies; they documented an association between high serum OPG levels and cardiovascular disease [46, 47]. Pennisi et al. found that patients with plaques in both carotid and femoral districts showed a significant association between OPG serum levels and the number of plaques [48]. They suggested that OPG could be useful in refining risk prediction of CVD (cardiovascular disease) in postmenopausal women with an associated occurrence of plaques in femoral/carotid arteries [48].

The current work suggested that serum OPG levels were a significant predictor of T2DM among obese patients. It is proposed that inflammation could link OPG to IR, the hallmark of obesity and T2DM, which considered a state of low-grade chronic systemic inflammation [49]. It has been suggested that OPG/RANK/RANKL pathway may play a role in the regulation of inflammatory and immune responses and directly regulate the production of proinflammatory cytokines from macrophages [50]. So, this pathway may have a role in DM pathogenesis.

In conclusion, the increased circulating OPG expression in obese women, especially diabetic obese patients could approve the link between inflammation, obesity indices (BAI and VAI) and MetS parameters. The identification of optimum cutoff of OPG expression and serum levels among obese patients could help in evaluating obesity and its comorbidities to decrease health hazards related to obesity. Further future multicenter studies with a bigger sample size are needed to confirm our findings.

Author contributions All authors contribute to study design, writing, methods, collection of data and its analysis.

Data availability The data used to support the findings of this study are included within the manuscript.

\section{Declarations}

Conflict of interest The author declare that they have no conflict of interest.

Consent to participate Written consent was obtained from all participants. The research ethics committee of our institutes approved the study. The work was done according to The Code of Ethics of the World Medical Association (Declaration of Helsinki) for studies involving humans.

Consent to publish All authors approved the current state of this manuscript.

\section{References}

1. Yamaoka K, Tango T (2012) Effects of lifestyle modification on metabolic syndrome: a systematic review and meta-analysis. BMC Med 10:138-148

2. Walther G, Obert P, Dutheil F et al (2015) Metabolic syndrome individuals with and without type 2 diabetes mellitus present generalized vascular dysfunction: cross-sectional study. Arterioscler Thromb Vasc Biol 35(4):1022-1029

3. Alebshehy R, Shuaib NM, Mbako JD et al (2016) Determinant analysis of obesity among adult females in Egypt. Egypt J Hosp Med 65(1):662-669

4. Garvey WT (2010) Clinical definition of overweight and obesity. Bariatric Endocrinology. Springer, Berlin, pp 121-143

5. Bergman RN, Stefanovski D, Buchanan TA et al (2011) A better index of body adiposity. Obesity 19:1083-1089

6. Amato MC, Giordano C, Galia M et al (2010) Visceral Adiposity Index: a reliable indicator of visceral fat function associated with cardiometabolic risk. Diabetes Care 33:920-922

7. Esser N, Legrand-Poels S, Piette J et al (2014) Inflammation as a link between obesity, metabolic syndrome and type 2 diabetes. Diabetes Res Clin Pract 105:141-150

8. Cawley KM, Bustamante-Gomez NC, Guha AG et al (2020) Local production of osteoprotegerin by osteoblasts suppresses bone resorption. Cell Rep 32:108052

9. Musialik K, Szulińska M, Hen K et al (2017) The relation between osteoprotegerin, inflammatory processes, and atherosclerosis in patients with metabolic syndrome. Eur Rev Med Pharmacol Sci 21(19):4379-4385

10. Aramburu-Bodas O, García-Casado B, Salamanca-Bautista P et al (2015) Relationship between osteoprotegerin and mortality in decompensated heart failure with preserved ejection fraction. J Cardiovasc Med 16(6):438-443

11. López-Mejias R, Ubilla B, Genre F et al (2015) Osteoprotegerin concentrations relate independently to established cardiovascular disease in rheumatoid arthritis. J Rheumatol 42(1):39-45. https://doi.org/10.3899/jrheum.140690

12. Nesaee N, Sharifzadeh G, Hoseini M et al (2021) Comparison of serum levels of osteoprotegerin, insulin, triglyceride, and cholesterol in obese and non-obese children. Int J School Health 8:141-147

13. Kalkan R, Becer E (2019) RANK/RANKL/OPG pathway is an important for the epigenetic regulation of obesity. Mol Biol Rep 46(5):5425-5432

14. Xu F, Li W, Yang X (2021) The roles of epigenetics regulation in bone metabolism and osteoporosis. Front Cell Dev Biol. https://doi.org/10.3389/fcell.2020.619301

15. Friedewald WT, Levy RI, Fredrickson DS (1972) Estimation of the concentration of low-density lipoprotein cholesterol in plasma, without use of the preparative ultracentrifuge. Clin Chem 18:499-502

16. Poubelle PE, Chakravarti A, Fernandes MJ et al (2007) Differential expression of RANK, RANK-L, and osteoprotegerin by synovial fluid neutrophils from patients with rheumatoid arthritis and by healthy human blood neutrophils. Arthritis Res Ther 9(2):R25

17. Walsh MC, Choi Y (2014) Biology of the RANKL-RANK-opg system in immunity, bone, and beyond. Front Immunol 5:511

18. Takai H, Kanematsu M, Yano K et al (1998) Transforming growth factor- $\beta$ stimulates the production of osteoprotegerin/osteoclastogenesis inhibitory factor by bone marrow stromal cells. J Biol Chem 273:27091-27096

19. Chung ST, Geerts D, Roseman K et al (2017) Osteoprotegerin mediates tumor-promoting effects of Interleukin-1beta in breast cancer cells. Mol Cancer 16:27 
20. Makiishi-Shimobayashi C, Tsujimura T, Iwasaki T et al (2001) Interleukin-18 up-regulates osteoprotegerin expression in stromal/ osteoblastic cells. Biochem Biophys Res Commun 281:361-366

21. Hofbauer LC, Gori F, Riggs BL et al (1999) Stimulation of osteoprotegerin ligand and inhibition of osteoprotegerin production by glucocorticoids in human osteoblastic lineage cells: potential paracrine mechanisms of glucocorticoid-induced osteoporosis. Endocrinology 140:4382-4389

22. Onyia JE, Miles RR, Yang X et al (2000) In vivo demonstration that human parathyroid hormone 1-38 inhibits the expression of osteoprotegerin in bone with the kinetics of an immediate early gene. J Bone Miner Res 15:863-871

23. Brandstrom H, Jonsson KB, Ohlsson C et al (1998) Regulation of osteoprotegerin mRNA levels by prostaglandin E2 in human bone marrow stroma cells. Biochem Biophys Res Commun 247:338-341

24. Jia J, Zhou H, Zeng X et al (2017) Estrogen stimulates osteoprotegerin expression via the suppression of miR-145 expression in MG-63 cells. Mol Med Rep 15(4):1539-1546

25. Holecki M, Zahorska-Markiewicz B, Janowska J et al (2007) The influence of weight loss on serum osteoprotegerin concentration in obese perimenopausal women. Obesity 15(8):1925-1929

26. Suliburska J, Bogdanski P, Gajewska E et al (2013) The association of insulin resistance with serum osteoprotegerin in obese adolescents. J Physiol Biochem 69(4):847-853

27. Erol M, Gayret OB, Nacaroglu HT et al (2016) Association of osteoprotegerin with obesity, insulin resistance and non-alcoholic fatty liver disease in children. Iran Red Crescent Med J 18(11):e41873

28. Zaky DS, Ali AA, Abd-Elraheem SE et al (2019) Circulating osteoprotegerin level in relation to obesity in middle aged females. Int J Prev Treat 8(2):41-45

29. Stanik J, Kratzsch J, Landgraf K et al (2019) The bone markers sclerostin, osteoprotegerin, and bone-specific alkaline phosphatase are related to insulin resistance in children and adolescents, independent of their association with growth and obesity. Horm Res Paediatr 91(1):1-8

30. Ayina CN, Sobngwi E, Essouma $\mathrm{M}$ et al (2015) Osteoprotegerin in relation to insulin resistance and blood lipids in sub-Saharan African women with and without abdominal obesity. Diabetol Metab Syndr 7(1):1-4

31. Gannagé-Yared MH, Yaghi C, Habre B et al (2008) Osteoprotegerin in relation to body weight, lipid parameters insulin sensitivity, adipocytokines, and C-reactive protein in obese and non-obese young individuals: results from both cross-sectional and interventional study. Eur J Endocrinol 158(3):353-359

32. Kotanidou EP, Kotanidis CP, Giza S et al (2019) Osteoprotegerin increases parallel to insulin resistance in obese adolescents. Endocr Res 44(1-2):9-15

33. Toffoli B, Fabris B, Bartelloni G et al (2016) Dyslipidemia and diabetes increase the OPG/TRAIL ratio in the cardiovascular system. Mediators Inflam 2016:6529728

34. Chang YH, Lin KD, He SR et al (2011) Serum osteoprotegerin and tumor necrosis factor related apoptosis inducing-ligand (TRAIL) are elevated in type 2 diabetic patients with albuminuria and serum osteoprotegerin is independently associated with the severity of diabetic nephropathy. Metabolism 60(8):1064-1069

35. Brion C, Lutz SM, Albert FW (2020) Simultaneous quantification of mRNA and protein in single cells reveals post-transcriptional effects of genetic variation. Elife 16(9):e60645
36. Fan S, Wang Z, Li Q et al (2020) The relationship between BSP mRNA expression and $25(\mathrm{OH})$ D/OPG in peripheral blood of newly diagnosed T2DM patients with different bone mass. Endokrynol Pol 71(2):160-167

37. Szymańska M, Michałus I, Kaszkowiak M et al (2020) Metabolic bone markers can be related to preserved insulin secretion in children with newly diagnosed type 1 diabetes. Pediatr Endocrinol Diabetes Metab 26:10-16

38. Karalazou P, Ntelios D, Chatzopoulou F et al (2019) OPG/RANK/ RANKL signaling axis in patients with type I diabetes: associations with parathormone and vitamin D. Ital J Pediatr 45:161

39. Ahmed MB, Ismail MI, Meki AR (2015) Relation of osteoprotegerin, visfatin and ghrelin to metabolic syndrome in type 2 diabetic patients. Int J Health Sci 9(2):127-139

40. Alharbi AS, Banjar ZM, Shenawy OM, et al. (2015) Osteoprotegerin level in Saudi obese with insulin resistance and diabetic type 2 patients. ZU M J 19(2)

41. Pereira GB, Tibana RA, Navalta J et al (2013) Acute effects of resistance training on cytokines and osteoprotegerin in women with metabolic syndrome. Clin Physiol Funct Imaging 33(2):122-130

42. Gümüş A, Düz ME, Coşkun C et al (2019) Evaluation of receptor activator of nuclear factor kappa-B ligand and osteoprotegerin levels in patients with type 2 diabetes mellitus treated with oral anti-diabetics (sulfonylurea and metformin) or insulin: bone tissue perspective. İstanbul Med J 20(2):130

43. Sassi F, Buondonno I, Luppi C et al (2018) Type 2 diabetes affects bone cells precursors and bone turnover. BMC Endocr Disord 18(1):1-8

44. Rashad NM, El-Shal AS, Abdelaziz AM (2013) Association between inflammatory biomarker serum procalcitonin and obesity in women with polycystic ovary syndrome. J Reprod Immunol 97(2):232

45. Rashad NM, El-Shal AS, Etewa RL et al (2017) Lipocalin-2 expression and serum levels as early predictors of type 2 diabetes mellitus in obese women. IUBMB Life 69(2):88-97

46. Miramontes-González JP, Usategui-Martín R, de Isla LP et al (2019) VEGFR2 and OPG genes modify the risk of subclinical coronary atherosclerosis in patients with familial hypercholesterolemia. Atherosclerosis 285:17-22

47. Tschiderer L, Klingenschmid G, Nagrani R et al (2018) Osteoprotegerin and cardiovascular events in high-risk populations: meta analysis of 19 prospective studies involving 27,450 participants. J Am Heart Assoc 7(16):e009012

48. Pennisi P, Russo E, Gaudio A et al (2010) The association between carotid or femoral atherosclerosis and low bone mass in postmenopausal women referred for osteoporosis screening does osteoprotegerin play a role? Maturitas 67(4):358-362

49. Chen L, Chen R, Wang H, Liang F (2015) Mechanisms linking inflammation to insulin resistance. Int J Endocrinol 28:2015

50. Shimamura M, Nakagami H, Osako MK et al (2014) OPG/ RANKL/RANK axis is a critical inflammatory signaling system in ischemic brain in mice. Proc Natl Acad Sci USA 111(22):8191-8196

Publisher's Note Springer Nature remains neutral with regard to jurisdictional claims in published maps and institutional affiliations. 